\title{
COMPORTAMENTO FENOLÓGICO DA SUCUPIRA-PRETA (Diplotropis purpurea (Rich.) Amsh. var. coriacea Amsh.), NA RESERVA FLORESTAL DUCKE.
}

\author{
César Leandro Abozaglo UMAÑ̃A ${ }^{1}$, Jurandyr da Cruz ALENCAR ${ }^{2}$
}

\begin{abstract}
RESUMO - Este trabalho analisa dados de 6 anos (1980-1985) de observações da fenologia de cinco indivíduos arbóreos da espécie Diplotropis purpures (Rich.) Amsh. var. coriacea Amsh., da família Leguminosae, subfamília Papilionoideae, localizados na Reserva Florestal Ducke. Determinou-se a época, duração e frequência das fases reprodutivas, bem como o tipo de mudança foliar. A espécie apresentou a fase de floração na estação seca. A fase de frutificação foi observada no meio da estação seca e início da estação chuvosa. A duração média da fase de floração foi de 6 meses e a fase de frutificação 7 meses. Ao nível de espécie, o padrão de ocorrência da fase de floração e frutificação foi anual à irregular. Porém, ao nível de indivíduo, o padrão de comportamento foi irregular. Quanto ao tipo de mudança foliar, a espécie apresentou características de ser semi-caducifólia durante a floração, na época seca.
\end{abstract}

Palavras-chave: Fenologia, espécie arbórea, floresta tropical.

Phenological Behavious of Sucupira-preta (Diplotropis purpurea (Rich.) Amsh. var. coriacea Amsh.), in Ducke Forest Reserve.

ABSTRACT - This work analyses phenological data during the period from 1980 to 1985 of Diplotropis purpurea (Rich.) Amsh. var coriacea Amsh. - Leguminosae - Papilionoideae, located at Ducke Forest Reserve, including flowering, fruiting and leaf change. The period of time, duration and frequency of reproductive phases are reported, as well as the type of leaf change. The species showed the flowering phase in the dry season. The fruiting phase was observed in the middle of dry season and at the beginning of wet season. The duration of the flowering and fruiting was about 6 and 7 months. In reference to the occurrence of flowering and fruiting both were annual to irregular, although at the individual level the behavior was irregular. Considering the leaf changes the species showed a semi-deciduous pattern during the flowering, in the dry season.

Key-words: Phenology, woody species, tropical rain forest.

\section{INTRODUÇÃO}

Vários resultados fenológicos de espécies arbóreas nativas da Reserva Florestal Ducke já foram relatados por ARAÚJO (1970), ALENCAR et al. (1979), MAGALHÃES \& ALENCAR (1979), ALENCAR (1984; 1988; 1990); 1991), LIMA JUNIOR (1992) e LIMA JUNIOR \& ALENCAR (1992).
Dentre as espécies em estudo na Reserva Ducke, a Sucupira-preta (Diplotropis purpurea) inclui-se como uma espécie promissora e alternativa para a indústria madeireira por apresentar lenho duro e resistente e, por isso, utilizada na fabricação de dormentes, em marcenaria, construção civil e naval (SILVA et al, 1977). O estudo da fenologia está diretamente

Eng ${ }^{\circ}$ Florestal, bolsista do CNPQ - INPA/CPST

2 Instituto Nacional de Pesquisas da Amazônia. Coordenação de Pesquisa em Silvicultura Tropical 
ligado ao conhecimento da biologia reprodutiva e estrutura genética das espécies, sendo de grande importância para o manejo florestal, e o insucesso dos métodos de manejo baseados na regeneração é em grande parte devido a ignorância sobre a biologia reprodutiva das espécies (BAWA \& KRUGMAN, 1991).

FOURNIER (1974) relatou que o conhecimento periódico dos eventos fenológicos pode possibilitar um melhor entendimento da vegetação, indicando o seu papel nas cadeias alimentares. Apesar do valor científico e até mesmo econômico destas informações a pesquisa neste campo ainda é bastante escassa, porém tem sido considerada por alguns pesquisadores (RICHARDS, 1973; FOURNIER, 1974; TOMLINSON \& LONGMAN, 1983; apud CARDOSO, 1991), como de grande importância no campo silvicultural, permitindo prever épocas de reprodução e o ciclo de crescimento vegetativo. Para FOURNIER (1967), os estágios fenológicos de uma determinada espécie são de grande importâcia para o entendimento da dinâmica dessa comunidade, assim como possiveis indicadores das condições climáticas e edáficas de um ambiente.

Sobre o comportamento fenológico desta espécie, a literatura consultada não cita nada a respeito, impossibilitando a obtenção de subsídios científicos sobre a biologia da espécie no seu habitat natural e determinação da melhor época para coleta de sementes, capazes de orientar o seu manejo silvicultural. Daí a importância do presente estudo.

\section{MATERIAL E MÉTODOS}

\section{Área de estudo}

O estudo foi realizado na Reserva Florestal Ducke, localizada no Km 26 da Rodovia Manaus-Itacoatiara, numa área de aproximadamente 300 hectares. A área da reserva é de 10.072 hectares, de floresta tropical úmida de terra firme, e está compreendida entre as coordenadas $59^{\circ} 52^{\prime} 40^{\prime \prime}$ e $59^{\circ} 58^{\prime} 00^{\prime \prime}$ de longitude oeste e $03^{\circ} 00^{\circ} 00^{\prime \prime} \mathrm{e}$ $03^{\circ} 08^{\circ} 00^{\prime \prime}$ de latitude sul (RIBEIRO. 1976).

O clima da área é do tipo Afi, de acordo com a classificação de KOPPEN: A - clima tropical praticamente scm inverno, cuja temperatura média para o mês mais frio nunca é inferior a $18^{\circ} \mathrm{C}$ : F - chuvas durante todo o ano: I - indica isotermia, ou seja, as oscilações anuais de temperatura média não chegam a $5^{\circ} \mathrm{C}$; não há propriamente verão nem inverno (RIBEIRO,1976).

O solo predominante na área é o Latossolo amarelo distrófico, caracterizado por possuir horizonte $\mathrm{A}$ órico $\mathrm{e}$ horizonte $\mathrm{B}$ óxido em perfil natural e baixa saturação em bases. São solos ácidos, com boa drenagem e resistentes à erosão. Estes solos originam-se de rochas graníticas do Pré-cambriano, ou de sedimentos do Cretáceo e de sedimentos argilosos ou argilo-arenosos do Terciário, do Pleistoceno (RANZANI. 1979).

A floresta é do tipo tropical úmida de terra-firme, caracterizada pela grande diversidade de espécies arbóreas, arbustivas e herbáceas (ALENCAR, 1986). 


\section{Características da espécie}

POLHILL (1981) considerou as leguminosas como uma das maiores familias dentre as fanerógamas, com cerca de 650 gêneros, 18000 espécies e aceitou a divisão da familia em três subfamilias como tradicionalmente reconhecidas: Mimosoideae, Caesalpinoideae e Papilionoideae. Porém, alguns estudiosos do grupo (HUTCHINSON, 1964; BANDEL, 1972; apud MESQUITA 1990) as consideraram como três familias botanicamente independentes e distintas (Mimosaceae, Caesalpiniaceae e Fabaceae, pertencentes à ordem Leguminales). Entretanto, preferiu-se acatar as considerações de POLHILL (1981), o qual mantém o grupo das leguminosas em uma única família Leguminoseae, dividida em três subfamílias, todas na ordem Rosales. Assim, classificou-se Diplotropis purpurea como sendo da Família Leguminoseae e subfamília Papilionoideae. As madeiras que compõe o grupo conhecido por Sucupira são representadas por espécies pertencentes aos gêneros Bowdichia ( $B$. nitida e $B$. virgilioides) e Diplotropis (D. purpurea, D. racemosa e D. martiusii). As diferenças anatômicas existentes entre elas são pouco perceptíveis, sendo consideradas, no comércio, como variações da própria madeira (JANKOWSKY et al., 1990; MAINIERI \& CHIMELO, 1989).

Diplotropis purpurea é freqüente na mata de terra-firme em solo argiloso, nas margens dos campos e nas ilhas de mata (LOUREIRO et al., 1979; SILVA et al., 1977).

Árvore pequena nos campos, mediana ou grande na mata, (10-15 m de altura por $25-30 \mathrm{~cm}$ de diâmetro), belíssima quando coberta de flores. $\mathrm{Na}$ mata, as árvores antigas podem atingir até $45 \mathrm{~m}$ de altura e $120 \mathrm{~cm}$ de diâmetro, sendo no capoeirão de menor porte (JANKOWSKY et al, 1990). Segundo SILVA et al. (1977) as Flores apresentam-se em inflorescência densamente rufo-tomentosa e o Frutos são legumes membranáceos, translúcidos, branco esverdeados (Fig. 1). Outras informações botânicas e sobre a anatomia da madeira são encontradas em SILVA et al. (1977) e LOUREIRO et al. (1979).

\section{Coleta e Análise dos Dados}

Os dados foram coletados abrangendo as fenofases de floração, frutificação e mudança foliar, por um período de 6 anos (1980 - 1985) seguindo a metodologia exposta na Tabela 1, conforme ARAÚJO (1970). Cinco árvores de Diplotropis purpurea foram escolhidas na floresta levandose em consideração os seguintes fatores: árvore madura com ótimas características fenotípicas.

As observações fenológicas foram realizadas mensalmente, com o auxílio de um binóculo do tipo $\mathrm{E}$. LEITZ - 7x50. Coletou-se material botânico de cada árvore para identificação no Herbário do INPA (Fig. 1).

Os dados de campo foram digitados em computador por meio do programa DBASE III, e analisados 


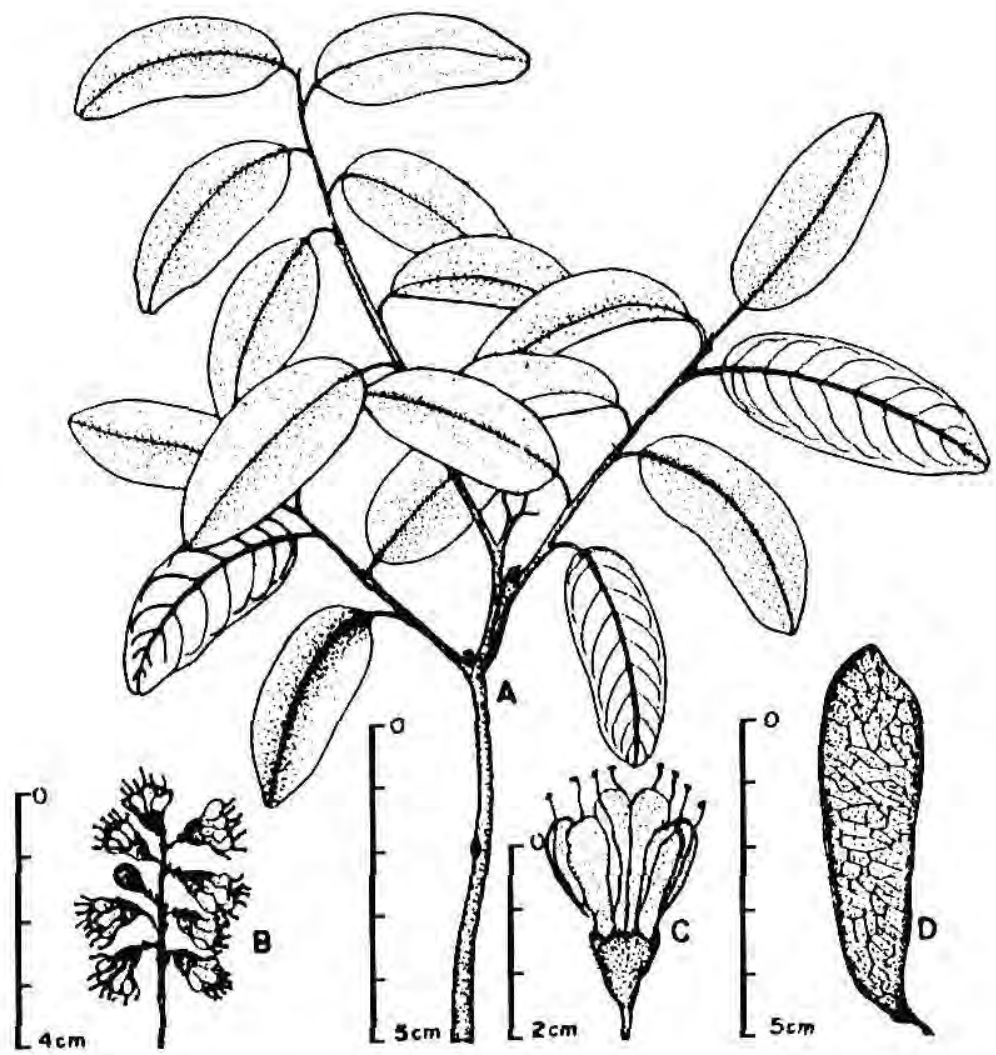

Figura 1 Diplotropis purpurea (Rich.) Amsh. var. coriacea Amsh. $\mathrm{A}$ - ramo $\mathrm{B}$ - inflorescência $\mathrm{C}$ - flôr D - Fruto

Tabela 1. Quadro de observações fenológicas

\begin{tabular}{cl}
\hline FENOFASE & \multicolumn{1}{c}{ FLORAÇĀO } \\
\hline 1 & BOTÖES FLORAIS APARECENDO \\
2 & FLORAÇĀO ADIANTADA, ÁRVORE TOTALMENTE FLORADA \\
3 & FLORAÇÃO TERMINADA OU TERMINANDO \\
& \multicolumn{1}{c}{ FRUTIFICAÇÃO } \\
4 & FRUTOS NOVOS APARECENDO \\
5 & FRUTOS MADUROS PRESENTES \\
6 & FRUTOS MADUROS CAINDOE SEMENTES DISPERSADAS \\
& MUDANÇA FOLIAR \\
7 & POUCAS FOLHAS OU DESFOLHADAS \\
8 & FOLHAS NOVAS APARECENDO \\
10 & MAIORIA DAS FOLHAS NOVAS OU TOTALMENTE NOVAS \\
\hline
\end{tabular}


pelo programa FENOLOG desenvolvido no CPST/INPA, o qual forneceu as porcentagens médias de ocorrência mensal das fenofases. De posse desses resultados, foram gerados gráficos de cada fenofase por meio de uma Planilha de Cálculo.

Os dados meteorológicos referentes ao período de seis anos (1980-1985) foram cedidos pelo Setor de Meteorologia e Climatologia da Coordenação de Pesquisa em Ciências do Ambiente do INPA, registrados pela Estação Meteorológica localizada dentro da própria área deste estudo. As variáveis climáticas (Precipitação, Insolação, Evaporação e Temperaturas máximas, mínimas e médias) são apresentadas em valores médios mensais, referentes ao periodo estudado, para caracterizar os meses das duas estações (seca echuvosa) que ocorrem nesta região. Não foi feita nenhuma correlação dos valores das fenofases com estas variáveis.

\section{Conclusões}

A fase de floração, decorrida desde o aparecimento dos botões florais até a queda das últimas pétalas, ocorreu durante a estação seca (julho a dezembro). A Plena floração ocorreu um mês após o aparecimento dos botões florais, apresentando picos de ocorrência nos meses de agosto e novembro. Durante a floração (época seca), os individuos estavam quase que totalmente sem suas folhas, recuperando-as no inicio da estação chuvosa. Um mês após a plena floração já podiam ser encontrados frutos novos, com pico de ocorrência em setembro.
Ao nível de espécie, foi encontrado com maior freqüência o padrão anual à irregular, da ocorrência da floração, porém, ao nivel de indivíduo, observou-se maior incidência do padrão irregular, sem alguns indivíduos apresentarem a fenofase durante o período estudado.

Foram encontrados frutos maduros no final da estação seca e início da estação chuvosa, com picos de ocorrência nos meses de janeiro e fevereiro. Para a coleta de sementes, a época mais apropriada seria nos meses de janeiro a março. A fase de frutificação, decorrida desde o aparecimento de frutos novos até a dispersão das sementes, ocorreu com maior freqüência entre os meses de setembro a março (7 meses), num período maior que a floração (6 meses). Nos meses de abril a agosto a frutificação foi nula.

A mudança foliar foi predominante no meio da estação seca, com o pico dos indivíduos com poucas folhas no mês de setembro $(50 \%)$. Durante este periodo a presença de folhas velhas também foi observada, porém em menor porcentagem, caracterizando Diplotropis purpurea como espécie semi-caducifólia, durante a floração. A presença de folhas velhas ocorreu durante o ano todo, com maiores valores médios em março e agosto.

\section{RESULTADOS E DISCUSSÃO}

\section{Meteorologia}

Os meses de junho, julho, agosto, setembro, outubro e noveinbro apresentaram os menores valores de 
precipitação, maior insolação e evaporação, caracterizando-se como representantes da estação seca.

$\mathrm{O}$ mês de menor precipitação foi julho com a média de $95,9 \mathrm{~mm}$ (Fig. 2).

Os demais meses (dezembro, janeiro, fevereiro, março, abril e maio) apresentaram maior precipitação, menor insolação e evaporação, caracterizando-se como representantes da estação das chuvas, sendo o mês de dezembro com maior média de precipitação, $288,3 \mathrm{~mm}$.

$\mathrm{O}$ total médio anual de precipitação para o período foi de $2261,9 \mathrm{~mm}$.

Quanto a temperatura média, verificou-se pouca variação (entre 25 a $26^{\circ} \mathrm{C}$ ), sendo que as maiores médias mensais de temperatura máxima corresponderam exatamente ao periodo sêco, alcançando em outubro o seu maior índice com $33,0^{\circ} \mathrm{C}$ (Fig. 3). As menores médias mensais de temperatura máxima foram nos meses chuvosos, com uma pequena oscilação, sendo o mês de janeiro o de menor índice, com $31,4^{\circ} \mathrm{C}$. A maior média das minimas, correspordeu a $22,3^{\circ} \mathrm{C}$ em novembro e a menor ao mês de julho com $21,3^{\circ} \mathrm{C}$. $\mathrm{O}$ valor médio anual de umidade relativa foi de $85 \%$ no período estudado.

\section{Floração}

A fenofase 1 (Botões florais aparecendo) de Diplotropis purpurea

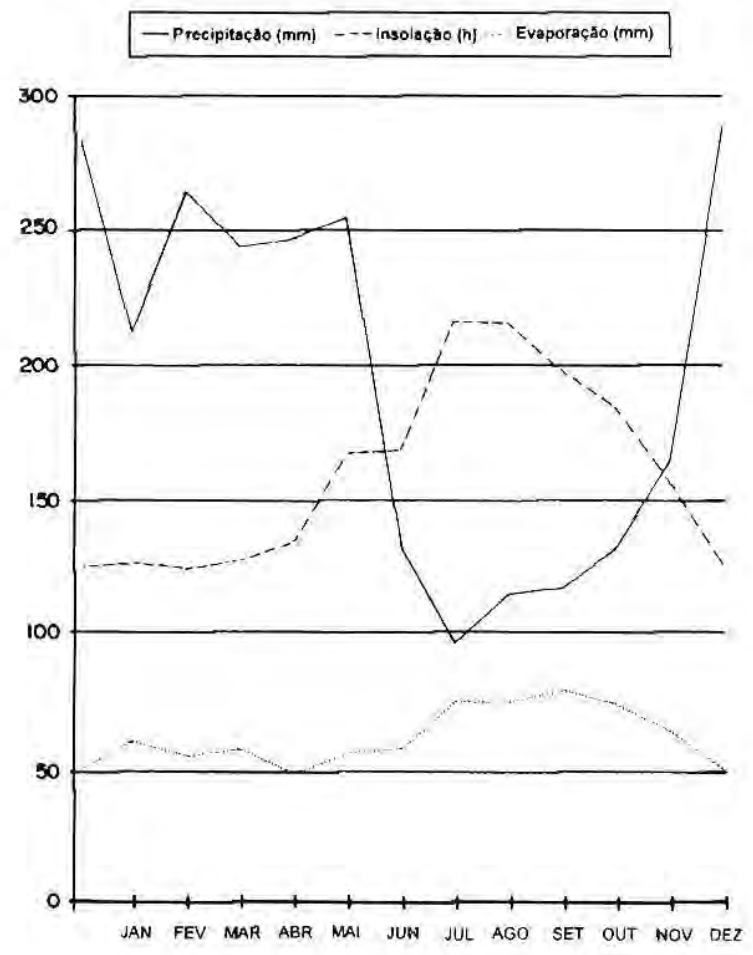

Figura 2. Dados meteorológicos da Reserva Ducke no período de 1980 a 1985 


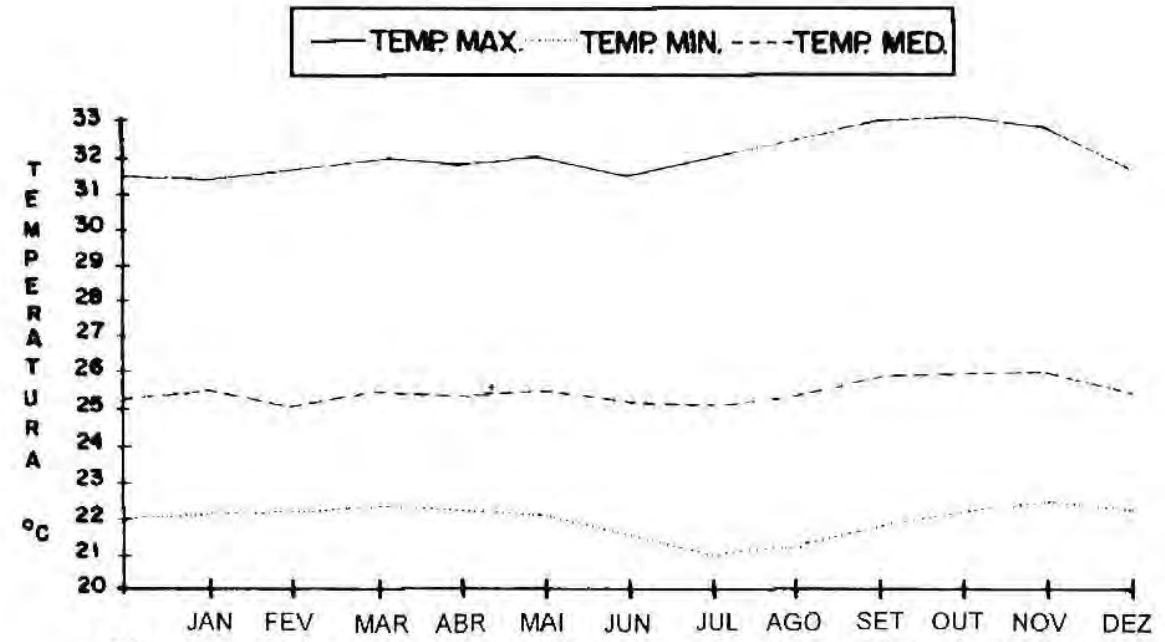

Figura 3. Dados meteorológicos da Reserva Ducke no período de 1980 a 1985

ocorreu na estação seca, com o pico da nula de janeiro a julho. A fenofase 3 ocorrência média mensal em outubro (Floração terminada ou terminando) $(40 \%)$. Nos meses de dezembro a junho apresentou picos nos meses de agosto o aparecimento de botões florais foi $(33,33 \%)$, setembro $(33,33 \%)$ e nulo. A fenofase 2 (Floração adianta- novembro (33,33\%). A Figura 4 mosda) teve sua ocorrência na estação tra que a floração em conjunto, período seca, com maior porcentagem de que vai do aparecimento dos botões ocorrência média nos meses de agosto florais até o término da floração, $(33,33 \%)$ e novembro $(33,33 \%)$, sendo ocorreu de julho a dezembro.

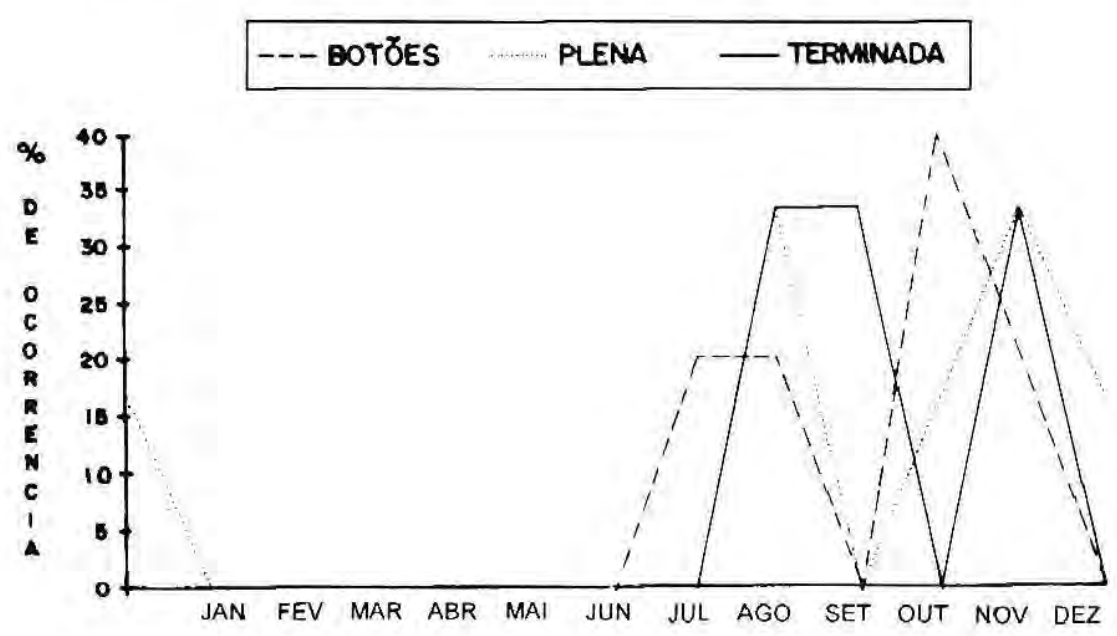

Figura 4. Ocorrência média mensal (\%) proporcional a cinco individuos das fases de floração de Diplotropis purpurea, durante 6 anos de observação (1980-1985) 
A análise dos dados de floração (Tab. 2) mostra que, ao nível de espécie, foi encontrado com maior freqüência o padrão anual a irregular. Porém, ao nível de indivíduo, observou-se maior incidência do padrão irregular, com variação de até 6 anos sem os individuos apresentarem a fase. $\mathrm{A}$ indução floral em árvores tropicais parece ser influenciada por causas endógenas e afetada por fatores ambientais (exógenos), indiretamente, por meio dos seus efeitos sobre o desenvolvimento sazonal vegetativo das árvores, fato pelo qual muitas árvores precisam passar por um periodo juvenil prolongado antes de atingirem seu potencial de floraração e, uma vez maduras, não floram, conseqüentemente, todos os anos (BAWA \& KRUGMAN, 1991).

Tabela 2. Análise das fases de floração de Diplotropis purpurea, no periodo de 1980 a 1985, na Reserva Florestal Ducke, INPA Manaus.

\begin{tabular}{ll}
\hline \multicolumn{1}{c}{ FLORAÇÃO } & PERIODO MĖDIO \\
\hline Épóca de floração plena & Agosto a novembro \\
Pico da floração plena & Agosto e novembro \\
Duração da fase & Julho a dezembro \\
Padrão anual da espécie & Anual a irregular \\
Padrão anual ao nivel individual & Irregular \\
\hline
\end{tabular}

Analisando as Figuras 4 e 6 , verifica-se que a fase de floração ocorreu com aumento da fenofase 7 (Árvores com poucas folhas ou desfolhadas) $\mathrm{e}$ fenofase 8 (Folhas novas aparecendo), confirmando o comentário de LOUREIRO et al. (1979): "No início da floração (meio da estação seca) a árvore despe-se quase que totalmente de suas folhas, para logo depois (no início da estação chuvosa) recuperá-las".
ALENCAR (1988), estudando Copaifera multijuga, verificou que a insolação foi significativa com a floração, apresentando coeficiente de regressão negativo, e o pico médio dos botões florais ocorreu no mês de janeiro (época chuvosa). ALENCAR (1988), apud (ALENCAR et al,, 1979), relatou ainda que, Acapu (Vouacapoua pallidor), Cumaru (Dipteryx odorata subsp. paniculata), Mulateiro (Peltogyne paniculata), todas pertencentes à família das leguminosas, diferiram do padrão geral observado para a maioria das espécies florestais já estudadas, florando também na estação chuvosa, nos meses de dezembro a abril.

Das cinco espécies de Lecythidaceae estudadas por LIMA JUNIOR (1992), na Reserva Florestal Ducke, apenas a Lecythis zabucaja teve o pico da plena floração na estação seca, em agosto e setembro, e as demais espécies tiveram na época chuvosa. Porém, ARAúJO (1970) relatou que das 36 espécies estudadas por ele na Reserva Florestal Ducke, a maior ocorrência da floração foi no período seco, com $52,77 \%$, contra $22,22 \%$ no periodo chuvoso, $\mathrm{Na}$ Reserva Biológica de Campina do INPA, ALENCAR (1990) concluiu que a plena floração também ocorreu com maior freqüência na estação seca $(40,75 \%)$.

Para Diplotropis purpurea o periodo da floração foi de 6 meses. ALENCAR et al. (1979), estudando 27 espécies na Reserva Florestal Ducke, encontraram uma variação de 
1 a 7 meses de duração desta fase. A floração parece ser afetada por fatores ambientais como fotoperiodismo ou temperatura. Há espécies, também, que não apresentam nítida relação entre $o$ padrão fenológico e os fatores ambientais. Muitos arbustos tropicais e árvores sempre verdes de crescimento contínuo nos trópicos, especialmente as espécies polinizadas por morcegos, floram o ano inteiro, embora com diferentes padrões a cada ano (LONGMAN \& JENIK, 1987).

As visitas às flores são distribuidas mais uniformemente nas regiões tropicais e o principal grupo de animais são os morcegos, pássaros, mariposas, borboletas, moscas, vespas e abelhas. Freqüentemente, os polinizadores são específicos para cada espécie vegetal (JANZEN, 1975).

\section{Frutificação}

A fenofase 4 (Frutos novos aparecendo) ocorreu no meio da estação seca, e início da estação chuvosa, sendo que o pico da ocorrência média mensal foi em setembro, com $40 \%$ (Fig. 5).

\section{A fenofase 5 (Frutos maduros} presentes) observou-se no final da estação seca, sendo que o pico de ocorrência média mensal ocorreu no início da época chuvosa, nos meses de janeiro e fevereiro com $60 \%$ (Tab. 2).

A fenofase 6 (Frutos maduros caindo e sementes dispersas) ocorreu no final da estação seca e início da estação chuvosa. Nos meses de outubro e novembro sua ocorrência média foi de $33,34 \%$, porém, o pico da fenofase ocorreu em fevereiro e março com $66,66 \%$.

Verificou-se que de modo geral a frutificação (fenofases 4,5 e 6 ) ocorreu com maior freqüência entre os meses de setembro a março, sendo nula entre abril a agosto. As Figuras 4 e 5 mostram, ainda, que a frutificação (7

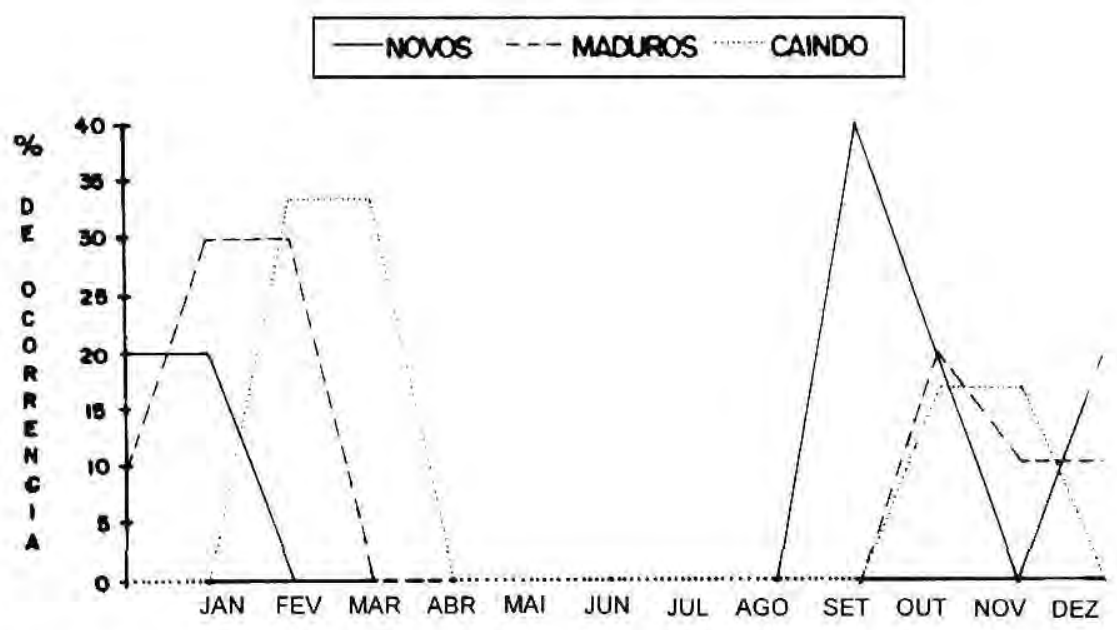

Figura 5. Ocorrência média mensal (\%) proporcional a cinco individuos das fases da frutificação de Diplotropis purpurea, durante 6 anos de observação (1980-1985) 
meses) ocorreu num período mais longo do que o da floração (6 meses). Em estudo realizado com 27 espécies arbóreas na Reserva Ducke, ALENCAR et al. (1979), observaram que a duração mais freqüente para as fases da frutificação foi de 5 meses, sendo sempre mais longa que as de floração.

Comparando-se as figuras 4 e 5 , observa-se que os picos da fenofase 2 (Floração adiantada ou plena) e fenofase 4 (Frutos novos aparecendo) são inversamente proporcionais, ou seja, quando ocorre o pico da plena floração (mês de agosto) observa-se que a fase defrutos novos é nula; no mês de setembro, quando o pico da floração plena é nula, ocorre o pico da floração terminada e frutos novos. Desta forma, verifica-se que um mês após a plena floração há possibilidade de serem encontrados frutos novos. Este comportamento também foi observado para a Anacardium spruceanum, Ocotea rubra, e Parkia pendula, por ARAÚJO (1970).

LIMA JUNIOR (1992), estudando cinco espécies de Lecythidaceae na mesma área, verificou que apenas Lecythis zabucaja e Lecythis pracei apresentaram "frutos novos" no final da estação seca e início da estação chuvosa. Na Amazônia, os "frutos maduros" são encontrados durante todo o ano, ocorrendo porém a maior produção na época chuvosa (ARAÚJO, 1970; ALENCAR et al., 1979; MAGALHÃES \& ALENCAR, 1979; ALENCAR, 1988). Foi observado também esse comportamento para o pico de produção de frutos de Diplotropis purpurea.

Apesar da frutificação ao nível de espécie ter sido anual à irregular, o padrão irregular foi predominante ao nivel de indivíduo (Tab. 3). Embora as espécies florestais tropicais possam florescer a cada ano, elas não produzem frutos freqüentemente (LONGMAN \& JENIK, 1974). O mesmo comportamento foi observado por LIMA JUNIOR (1992) para cinco espécies da familia Lecythidaceae. Aniba duckei sofreu intensa predação de seus frutos por pássaros e, segundo MAGALHÃES \& ALENCAR (1979), a irregularidade de frutificação desta espécie poderia estar correlacionada com o controle da população destes pássaros. Para a Copaifera multijuga, entre outras espécies, a fase de frutificação ocorreu em intervalos de dois anos (ALENCAR, 1988), e Aldina heterophylla, em intervalos de três anos, na Campina sombreada (ALENCAR, 1990).

\section{Mudança foliar}

A mudança foliar foi predominante na segunda metade da estação seca, onde observou-se o pico da fenofase 7 (Árvores com poucas folhas ou

Tabela 3. Análise das fases de frutificação de Diplotropis purpurea, durante o periodo de 1980 a 1985, na Reserva Florestal Ducke, INPA - Manaus.

\begin{tabular}{ll}
\hline \multicolumn{1}{c}{ FRUTIFICAÇĀO } & PERIODO MÉDIO \\
\hline Época de frutos maduros & $\begin{array}{l}\text { Outubro a fevereiro } \\
\text { Janeiro e fevereiro }\end{array}$ \\
Pico da fenofase & $\begin{array}{l}\text { Outubro, novembro, } \\
\text { fevereiro, março }\end{array}$ \\
Dispersão de frutos & Setembro a março \\
& Anual à irregular \\
Periodo da fase & Irregular \\
\hline
\end{tabular}


desfolhada) no mês de setembro (50\%). A fenofase 8 (Folhas novas aparecendo) ocorreu quase que simultaneamente, com pico máximo em outubro $(44,44 \%)$, um mês após a fenofase 7 (Fig. 6). Entre setembro e outubro, a presença de folhas velhas também foi observada, porém em menor porcentagem de ocorrência, caracterizando, portanto, Diplotropis purpurea como espécie semi-caducifólia.

A fenofase 9 (Maioria das folhas novas ou totalmente novas) apresentou picos médios de novembro a dezembro, com máximo em dezembro e valores baixos de ocorrência entre abril a agosto (Tab. 4). A fenofase 10 (Árvores com folhas velhas), ocorreu durante o ano todo, apresentando maiores valores médios nos meses de março a agosto, com decréscimos nos meses de setembro a dezembro.

A queda das folhas se dá com maior intensidade no periodo seco (ARAÚJO, 1970), O mesmo resultado foi encontrado por ALENCAR et al.
(1979), que concluiram haver ainda queda de folhas durante o ano todo. Para muitas árvores decíduas das florestas tropicais amanutenção das folhas poderia tornar-se anti-econômica quando a umidade baixasse até certo grau (LONGMAN \& JENIK, 1987). Nas florestas tropicais, a senescência das folhas parece mais claramente induzida por "stress" da seca do que por comprimento do dia (DAUBENMIRE, 1972). KLINGE \& RODRIGUES, 1968 apud ALENCAR et al. (1979), também encontraram que a queda de detritos (folhas e outros) ocorre durante todo o ano, e a manta formada na estação seca (julho a outubro) correspondeu a $50 \%$ da produção anual.

ALENCAR (1988) concluiu que somente a temperatura máxima foi significativa em relação a fase de desfolhamento de Copaifera multijuga, a qual ocorreu na estação seca.

LONGMAN \& JENIK (I974) relataram que a queda das folhas pode

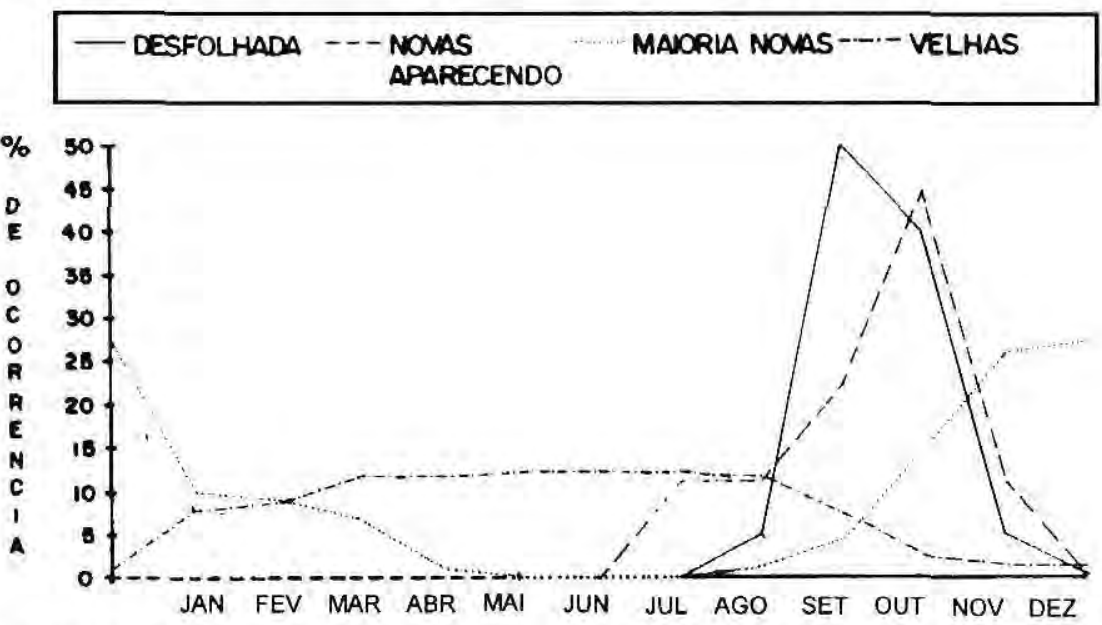

Figura 6. Ocorrência média mensal (\%) proporcional a cinco indivíduos das fases da mudança foliar de Diplotropis purpurea, durante 6 anos de observação (1980-1985) 
ser causada por muito fatores: baixa intensidade de luz, mudança de temperatura, comprimento do dia, dificiência mineral, redução no tecido fotossintético e de transpiração, tensão de água e danos causados por agentes mecânicos ou pragas.

Quanto ao aparecimento de folhas novas, LONGMAN \& JENIK (1974) e ALENCAR et al. (1979), observaram que nas florestas sempre verdes, a emissão das folhas ocorre freqüentemente na estação seca e os brotos emergem algum tempo antes das chuvas começarem. Analisando o comportamento fenológico de Copaifera multijuga e sua relação com o clima, ALENCAR (1988) concluiu que quando as árvores se encontram com a maioria das copas cobertas com folhas novas, as variáveis umidade relativa e insolação foram significativas, demonstrando serem elementos climáticos importantes na emissão de folhas novas.

A maior porcentagem de espécies nas florestas tropicais é das perenefólias, seguida das semi-caducifólias e por último das caducifólias (ARAÚJO, 1970; ALENCAR et al., 1979; ALENCAR, 1990). O comportamento de Diplotropis purpurea foi do tipo semi-caducifólio durante a floração, na estação seca, similar ao padrão relatado por ALENCAR et al. (1979), para várias espécies na Reserva Ducke.

\section{Bibliografia Citada}

ALENCAR, J . C. 1984. Estudos silviculturais de uma população natural de Copaifera multijuga Hayne - Leguminosae, na
Amazônia Central. 3. Distribuição espacial da regeneração natural préexistente. Acta Amazonica, 14 (12):255-279.

1986. Análise de associação e estrutura de uma comunidade de floresta tropical úmida onde ocorre Aniba rosaeodora Ducke (Lauraceae). Tese de Doutoramento em Ciências Biológicas. Curso de Pós-Graduação INPA/FUA. Apêndice: 207-337. 206p.

1988. Estudos silviculturais de uma popuiação natural de Copaifera multijuga Hayne - Leguminosae, na Amazônia Central. IV. Interpretação de dados fenológicos em relação a elementos climáticos. Acta Amazonica, 18(3-4):199-209.

1990. Interpretação fenológica de espécies lenhosas de campina na Reserva Biológica de Campina do INPA ao norte de Manaus. Acta Amazonica, 20 (único):145-183.

1991. Estudos fenológicos de espécies florestais arbóreas e de palmeiras nativas da Amazônia. In: ADALBERTO LUIS VAL, ROBERTO FIGLIUOLO, ELIANA FELDBERG. (eds.) Bases cientificas para estratégias de Preservação e Desenvolvimento da Amazônia: Fatos e Perspectivas. INPA, Manaus: 215-220.

ALENCAR, J. C., ALMEIDA, R.A. de \& FERNANDES, N, P. 1979. Fenologia de Espécies Florestais em Floresta Tropical úmida de Terra Firme na Amazônia Central. Acta Amazonica, 9(1):163-198.

ARAÚJO, V. C. 1970. Fenologia de Essências Florestais Amazônicas. I. Boletim do INPA, (4):25p. Manaus.

BAWA, K. S, \& KRUGMAN, S, L. 1991. Reproductive biology and genetics of Tropical Trees in Relation to conservation and management. In: GOMEZPOMPA, A.; WHITMORE, T. C. \& HADLEY, M.(Eds). Rain Forest Regeneration and Management. Man and biosphere (Series): 6, UNESCO, The Parthenon Group, Paris: 119-134. 
CARDOSO, N. S. 1991. Caracterização da estrutura anatômica da madeira, fenologia e relações com a atividade cambial de árvores de Teca (Tectona grandis L. F.) - Verbenaceae. Dissertação de Mestrado ESALQ/USP, Piracicaba. $117 \mathrm{p}$. "ilus.

DAUBENMIRE, R. 1972. Phenology and other characteristics of tropical semideciduous forest in North-Western Costa Rica. Journal of Ecology, 60(1):147170.

FOURNIER, L. A. 1967. Estudio preliminar sobre la floración en Roble de sabana, Tabebuia pentaphilla (L) Hemst. Revista Biologia Tropical, 15(2):259-67.

1974. Un método cuantitativo para la medición de la cacterísticas fenológicas en árboles. Turrialba, 24(4):422-23.

JANKOWSKY, I. P.; CHIMELO, J. P; CAVALCANTE, A. A, 1990, Madeiras brasileiras Caxias do Sul-RS. Spectrum Comunicação Ltda. $171 \mathrm{p}$.

JANZEN, D.H. 1975. Ecology of plants in the Tropics. Studies in Biology, 58. Edwar Arnold, London. 66p.

LIMA JUNIOR, M. J. V. 1992. Fenologia de cinco espécies de Lecythidaceae Reserva Florestal Ducke, Manaus-AM. Disser-tação de Mestrado INPA/FUA, Manaus. $72 p$.

LIMA JUNIOR, M. J. V. \& ALENCAR, J. C 1992. Fenologia de duas espécies do gênero Corythophora da família Lecythidaceae na Reserva Florestal Ducke, Manaus, AM. $2^{\circ}$ Congresso Nacional sobre essências nativas. Conservação da Biodiversidade. Secretaria do Meio Ambiente de São Paulo. SP.
LONGMAN, K. A. \& JENIK, J. 1974. Tropical forest and its environment. Tropical Ecology Series. London. 196p.

1987. Tropical forest and its environment. Longman Scientific \& Technical. $2^{s}$ ed. Nova York. $347 p$

LOUREIRO, A. A., SILVA, M. F. da \& ALENCAR, J. C. 1979. Essências madeireiras da Amazônia. Manaus: INPA. V.II.187p.

MAGALHÃES, L. M. S. \& ALENCAR, J. C. 1979. Fenologia do Pau-rosa (Aniba duckei Kostermans), Lauraceae, em Floresta Primária na Amazonia Central. Acta Amazonica, 9(2):227-232.

MAINIERI, C . \& CCHIMELO J. P. 1989. Fichas das caracteristicas das principais madeiras brasileiras. 2.ed. São Paulo. I.P.T. 420p.

MESQUTTA, A. L. 1990. Revisão taxonômica do gênero Enterolobium Mart. (Mimosoideae) para a região neotropical. Dissertação de Mestrado. UFRPE Recife, 222p, ilus.

POLHILL, R. M. 1981, Advances in Legume Systematics. Royal Botanic Gardens. Ministry of Agriculture. England. Part 1. $448 \mathrm{p}$.

RANZANI, G. 1979. Recursos pedológicos da Amazônia. Acta Amazonica, 9(4):2335 .

RIBEIRO, M. N. G. 1976. Aspectos Climatológicos de Manaus. Acta Amazonica, 6(2):229-233.

SILVA, M. F. da, LISBOA, P. L. B. \& LISBOA, R. C. L. 1977. Nomes vulgares de plantas amazônicas. Belém: INPA, 222p. 